\section{It's About Time!}

Just a few weeks ago, on October 30, 2017, CMS Administrator Seema Verma made a dramatic announcement at the Health Care Payment Learning \& Action Network (LAN) Fall Summit. She said that CMS was ready to engage in reforms that would "put patients first," starting with an initiative called "Patients Over Paperwork" to minimize regulatory burdens on doctors. You can read her speech on the CMS Web site (https://www.cms.gov/newsroom/mediareleasedatabase/fact-sheets/2017-fact-sheetitems/2017-10-30.html), so you know this is not "fake news."

Verma spoke of what you and I experience every day-requirements that force incessant documentation and meaningless hoops we must jump through to continue to be "qualified" to accept Medicare patients. And of course, it's not limited to CMS. Many other payers have their own "quality requirements." So we must serve many masters and keep track of each one's specific needs.

In addition to our time, there's a real cost to all this. Verma notes that the American Hospital Association estimates that $\$ 39$ billion USD are spent each year on administrative activities, and that an average hospital dedicates 59 full-time employees, including doctors and nurses, to regulatory compliance. Just think how far that money and person power could go if diverted to the patient experience instead!

Verma points a finger at the dreaded Medicare Access and CHIP Reauthorization Act of 2015 (MACRA) and acknowledges that these new requirements have unnecessarily overwhelmed and even confused us. And CMS is not even done rolling it out! But she stopped short of saying they would roll it back.

Instead, she introduced a new initiative, "Meaningful Measures," which was developed in collaboration with LAN, the National Academies of Medicine, the Core Quality Measure Collaborative, and the National Quality Forum. The new initiative is touted as being more streamlined, focused on just the core issues that are most vital for high-quality care and improved outcomes.

So far, so good, but what are the Meaningful Measures? I tried to look them up, but every link brought me back to her speech. Maybe it's a concept with details in development? Or maybe it's the process of streamlining what is already there? I honestly couldn't tell.

Verma also spoke of taking a hard look at the Innovation Center at CMS to see what is working and what is not. We in oncology have been inundated with many CMS "experiments," some of which overlap with existing ones or transition to others before anyone has really analyzed what transpired. And this hasn't been a very transparent process.

I do believe Verma is sincere and that something good will come of this. But we all know that measuring true quality is not easy. It is easy to document things. We can document that we asked about a patient's pain and did something about it. But how do we prove the patient actually felt better? That's been missing from all of this, in my opinion.

I applaud Verma and CMS for admitting that the regulations have gotten out of hand. I think we all have to agree that this isn't going to be easy. But let's hope that it is the start of real reform that really does put our patients first.

What do you think? Please e-mail correspondence (include contact information) to JNCCN@nccn.org or log into www.editiorialmanager.com/JNCCN to submit a Letter to the Editor.

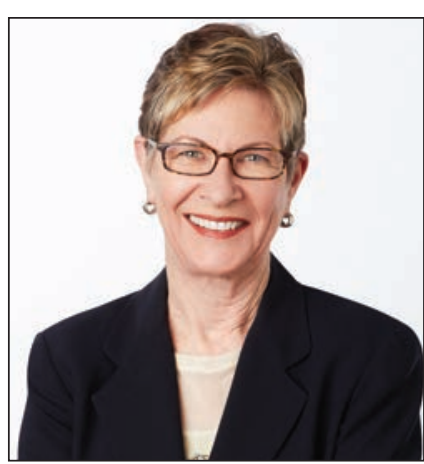

Margaret Tempero, MD

Margaret Tempero, MD, is a Professor of Medicine and Director of the UCSF Pancreas Center and editor-in-chief of JNCCN. Her research career has focused on pancreatic ductal adenocarcinoma, especially in the area of investigational therapeutics. Dr. Tempero has served on the ASCO Board of Directors and as ASCO President. She currently serves on the ASCO Conquer Cancer Foundation Board. She codirected the AACR/ASCO Methods in Clinical Cancer Research and taught this course and similar courses in Europe and Australia. She was founding Chair of the $\mathrm{NCl}$ Clinical Oncology Study Section and served as a member and Chair of the NCl Board of Scientific Counselors Subcommittee A. She is a member of the Scientific Steering Committee and Chair of the Clinical and Translational Study Section for the Cancer Prevention \& Research Institute of Texas. She is or has been on the Scientific Advisory Boards of the Lustgarten Foundation, the Pancreatic Cancer Action Network, the V Foundation, The Alberta Canada Cancer Board, and the EORTC. She served as a member of the Oncology Drug Advisory Committee for the FDA. She has served as Deputy Director and Interim Director for the UNMC Eppley Cancer Center. She is Chief Emeritus of the Division of Medical Oncology at UCSF and served as the founding Deputy Director and Director of Research Programs at the UCSF Helen Diller Family Comprehensive Cancer Center.

doi:10.6004/jnccn.2017.0177

The ideas and viewpoints expressed in this editorial are those of the author and do not necessarily represent any policy, position, or program of NCCN. 